\title{
Pharmacologic Management of Cough
}

\author{
Donald C. Bolser, PhD [Professor] \\ Dept. of Physiological Sciences, College of Veterinary Medicine, University of Florida, Gainesville, \\ FL, 32610-0144, Ph:352-294-4026, Fax:352-392-5145, bolser@vetmed.ufl.edu
}

\begin{abstract}
This review is an update of recent advances in our understanding of cough suppressants and impairment of cough. Low dose oral morphine has recently been shown to significantly suppress chronic cough, but the side effect profile of this opioid may limit its widespread utility. Several studies have demonstrated a dissociation between the efficacy of antitussives in some metrics of pathological cough and their effects on cough sensitivity to inhaled irritants. The relevance of widely used inhaled irritants in understanding pathological cough and its response to antitussives is questionable. A recent advance in the field is the identification and measurement of an index of sensation related to cough, the urge-to-cough. This measure highlights the potential involvement of suprapontine regions of the brain in the genesis and potential suppression of cough in the awake human. There are no new studies showing that mucolytic agents are of value as monotherapies for chronic cough. However, some of these drugs may be of use as adjunct therapies or in selected patient populations, presumably due to their antioxidant activity. The term dystussia (impairment of cough) has been coined recently and represents a common and life-threatening problem in patients with neurological disease. Dystussia is strongly associated with severe dysphagia and the occurrence of both indicates that the patient has a high risk for aspiration. There are no pharmacological treatments for dystussia, but the community of scientists and clinicians that have experience in studying chronic cough is uniquely well qualified to develop methodologies that enhance impaired cough.
\end{abstract}

\section{Keywords}

Cough; Antitussive; Cough suppressant; Dystussia; Atussia; Dysphagia

The purpose of this review is to provide an update on advances in the pharmacology of cough and antitussives. There are a number of informative reviews on recent work in the area of antitussives ${ }^{1-7}$. These reviews note the limited amount of new information that has become available on the effects of these drugs in humans in the last several years. Furthermore, there are no new drugs that have been shown to be effective as antitussive agents in double-blind placebo controlled trials in humans with chronic or acute cough ${ }^{2-6}$. This review will focus on some new information on antitussives. The review is expanded to include the potential therapeutic impact of enhancement of cough in patients that suffer from dystussia ${ }^{8}$, or impaired cough.

\footnotetext{
Publisher's Disclaimer: This is a PDF file of an unedited manuscript that has been accepted for publication. As a service to our customers we are providing this early version of the manuscript. The manuscript will undergo copyediting, typesetting, and review of the resulting proof before it is published in its final citable form. Please note that during the production process errors may be discovered which could affect the content, and all legal disclaimers that apply to the journal pertain.
} 


\section{Antitussives}

Our previous review9 as well as an earlier one10 noted that, in recent studies, commonly prescribed antitussives such as codeine and dextromethorphan had limited or no efficacy relative to placebo in humans with chronic cough. As such, these drugs were not recommended for suppression of cough. Since that time, a comprehensive study of the effect of codeine on chronic cough in patients with chronic obstructive pulmonary disease has been published 11 . This report confirmed a lack of efficacy of codeine to suppress cough in this patient group. However, Morice and coworkers ${ }^{12}$ have shown a $40 \%$ decrease in cough scores of an oral formulation of a low $(5 \mathrm{mg}$ ) dose of morphine. This dosing regime was well tolerated by their patients. Doubling this dose of morphine resulted in a higher frequency of side effects, such as sedation. The use of morphine as an antitussive is likely to be limited by widespread caution regarding the side effect liability of the drug ${ }^{5}$, regardless of how well tolerated this opioid is in any particular study.

The results of this study raise three additional important points:

1. It is possible to observe significant antitussive effects of an orally-active opioid in humans with chronic cough. The lack of efficacy of codeine (up to $60 \mathrm{mg}$ p.o.) in recent studies ${ }^{11}, 13$, may be related to specific issues with the molecule itself rather than $\mu$-opioid agonists in general. Indeed, the cough suppressant effects of codeine are not blocked by naloxone in the cat14, suggesting that this drug has actions at nonopioid receptors.

2. Although Morice et $\mathrm{al}^{12}$ showed activity of morphine to suppress cough scores in humans with chronic cough, the sensitivity of these patients to an inhaled irritant (citric acid) was not altered by the drug. Another study ${ }^{15}$ with dextromethorphan in smokers showed significant effects of this drug relative to placebo on cough sensitivity to inhaled citric acid, but there was no difference between active and placebo groups for subjective measures of coughing. These findings call to question the relevance of irritant aerosol challenge in the evaluation of the activity of putative cough suppressants in humans.

3. It is exceedingly difficult to prevent humans from coughing with an antitussive drug. This point should be considered in light of the widely held misconception that new cough suppressants should not be developed because they will eliminate the ability to protect the airway with the cough reflex.

An emerging trend in cough research is to expand our knowledge of the genesis of this airway protective behavior in humans. In particular, the effects of antitussives on sensory, motor, and mechanical aspects of cough have been a focus of several recent studies. The production of cough can be associated with significant sensations, termed urge-to-cough13, 16. In doseresponse studies with inhaled irritants13, these sensations occur in advance of the actual behavior and directly increase in intensity with the number of coughs and dose of irritant. Cough (and presumably the urge-to-cough) can be suppressed voluntarily17, 18, suggesting that there are endogenous neurochemicals in the human that can mediate this effect. Eccles and co-workers 17 showed that voluntary cough suppression is not opioid-mediated in humans. The presence of these sensations associated with the production of coughing indicates that this behavior is not simply an involuntary reflex phenomenon involving only brainstem mechanisms in the human. To be sure, vigorous chronic cough cannot be eliminated solely through voluntary means. However, pharmacological approaches that address sensory issues involved on the production of cough may yield novel cough suppressants. This argument is subject to the caveat that no information yet exists that demonstrates suppression of the urgeto-cough in humans with chronic cough by antitussives. In normal subjects, codeine (30 and $60 \mathrm{mg}$ ) did not alter cough sensitivity, electromyograms of abdominal muscles, airflows, or 
sensations associated with capsaicin-induced cough13. The role of urge-to-cough in the action of antitussive drugs in humans awaits specific studies that utilize effective cough suppressants.

In smokers, nicotine is thought to have a cough-promoting effect through its excitatory effects on pulmonary afferents ${ }^{19-21}$. In contrast, recent findings in smokers suggest that nicotine has a cough suppressant effect ${ }^{22}$. Smokers who refrained from smoking for 12 hours had greater levels of anxiety and higher cough responses and urge-to-cough ratings in response to inhalation of capsaicin than age-matched nonsmokers. When the smokers were administered nicotine gum during abstinence from smoking, anxiety levels, cough responses, and urge-tocough ratings were not different than placebo or the nonsmoking group ${ }^{22}$. The investigators concluded that nicotine modulated the central neural state of the smokers, which reduced anxiety, sensations, and cough responses. Regardless of mechanism, nicotine replacement normalized an elevated cough response and acted as a cough suppressant ${ }^{22}$. These results are consistent with other findings that spontaneous coughing increases in the subacute period following cessation of smoking ${ }^{23}$. This putative cough suppressant effect of nicotine may account for the ability of smokers to inhale cigarette smoke repeatedly each day without violent coughing. Nicotine penetrates the nervous system readily and the probability of a central action of this drug on the cough reflex in these subjects must be considered high.

In our previous review of this topic ${ }^{9}$, we concluded that mucolytic agents were not recommended to suppress cough in patients with chronic bronchitis. There may be other benefits of these drugs, such as increased cough clearance and improvement of other symptoms. We further recommended only one anticholinergic agent, ipratropium_bromide, for cough suppression ${ }^{9}$. Although new information related to some of these recommendations has appeared in the last several years, it does not appear that sufficient evidence has accumulated to warrant a change in these recommendations. New information has been published on several drugs with mucolytic or anticholinergic activity that have an antitussive effect in patients groups with chronic or acute cough.

$\mathbf{N}$-acetylcysteine was administered in a double-blind clinical trial to patients that had been exposed to sulfur-mustard gas ${ }^{24}$. This drug significantly improved cough, dyspnea, and several components of pulmonary function in these patients. Both the treatment and placebo groups received fluticasone and salmeterol, raising the possibility that $\mathrm{N}$-acetylcysteine had a synergistic effect with these drugs. The authors suggested that the antioxidant effects of this drug were responsible for its therapeutic effects ${ }^{24}$.

Another antioxidant agent and putative mucolytic agent, erdosteine, when combined with amoxicillin, has recently been shown to be significantly more effective in reducing cough in children with acute lower respiratory illness than this antibiotic and placebo ${ }^{25}$. This was a randomized double-blinded and placebo controlled study and the combination of erdosteine and amoxicillin reduced visual analog scores for cough by approximately $90 \%$ compared to $76 \%$ for amoxicillin plus placebo ${ }^{25}$. Note the large placebo effect which is typical for studies in which cough is an endpoint. Erdosteine also significantly decreased IL-8 in sputum of current smokers with $\mathrm{COPD}^{26}$, consistent with an anti-inflammatory effect.

These observations are consistent with the potential use of these drugs in combination therapies for the relief of cough in selected patient populations. Mucolytic drugs have not been effective as antitussive agents when used as monotherapies ${ }^{9}$. The extent to which these drugs will be useful for the suppression of cough on a widespread basis is unknown and awaits larger scale clinical trials.

A small scale double blind placebo controlled study was conducted on the effect of the anticholinergic agent, tiotropium, on cough due to acute upper airway viral infection ${ }^{27}$. Tiotropium significantly inhibited cough sensitivity to capsaicin after the first dose and out to 
seven days relative to placebo ${ }^{27}$. The treatment group also had significantly improved spirometry, but this effect was not correlated with cough sensitivity changes suggesting that bronchodilatation was not responsible for the effect on cough sensitivity. The cough suppressant activity of tiotropium in this study contrasts with the findings of Casaburi et $\mathrm{al}^{28}$, who showed no effect of this drug on cough in patients with COPD. As noted above, Morice et al ${ }^{12}$ showed that cough due to inhaled irritants is not an accurate predictor of the activity of antitussive drugs in patients with airway disease. The extent to which tiotropium will suppress spontaneous coughing in patients with acute upper airway viral illness is unknown. (Table 1)

\section{Enhancement of cough}

Awareness of the significance of dystussia is increasing. While chronic cough is associated with significant morbidity and quality of life issues ${ }^{6}$, dystussia is life-threatening ${ }^{29}, 30$. Dystussia and atussia ${ }^{8}$ represent a breakdown in endogenous mechanisms for airway protection. We define airway protection as the prevention and/or correction of aspiration. (Table 2). This process is accomplished through the expression of a constellation of different behaviors, which include cough, swallow, expiration reflex, laryngeal adduction, and apnea. During the pharyngeal phase of swallow, aspiration is prevented by closure of the vocal folds, changes in the breathing, elevation of the larynx, and movement of the epiglottis to protect the laryngeal orifice ${ }^{31}$. In awake humans, swallow preferentially occurs during the expiratory phase of breathing, usually resulting in a prolonged expiration and resetting of the breathing cycle $^{32}$. The expiration reflex prevents aspiration by changing breathing pattern and producing a ballistic-like expiratory airflow to "blow" adherent material away from the vocal folds ${ }^{33}$. If aspiration occurs, cough corrects this problem by the production of high velocity airflows that create shear forces to dislodge and eject material from the airway ${ }^{34}$.

In neurologic disease, airway protective mechanisms are frequently impaired, leading to increased risk of pulmonary infection. In patients with acute stroke or Parkinson's disease, those with dysphagia and aspiration also have profound dystussia ${ }^{8,} 35$. Furthermore, the risk of aspiration due to dysphagia can be predicted by several mechanical features of voluntary cough in stroke patients ${ }^{29}, 30$. These impairments of swallow and cough contribute to a high risk of aspiration 29 which "seeds" the subglottic airways with pathogen-laden material 36 resulting in a high prevalence of aspiration pneumonia. Mortality rates of aspiration pneumonia can approach $40 \%{ }^{29}$. High rates of aspiration also occur in patients following anterior cervical spinal surgery (over 40\%), in elderly patients in long term care facilities, those with gastrointestinal problems, and those with other neurological disorders such as Parkinson's Disease $^{29}$. Relationships have been objectively quantified between disordered swallow and dystussia in patients with Parkinson's Disease37.

Aspiration can occur with atussia and is termed "silent aspiration" 29 . Patients with silent aspiration have a 13 -fold increased risk of developing pneumonia ${ }^{38}$. By definition, patients with atussia and dysphagia have a high risk of developing pneumonia and this group exemplifies the consequences of impaired airway protection.

Atussia can occur with normal swallow in patients with cervical spinal injuries, leading to the development of pulmonary complications ${ }^{39}$. Pneumonia is one of the leading causes of death in this patient group ${ }^{39}$. Although intubation and mechanical ventilation represent strong contributors to the risk of pulmonary infection in patients with cervical spinal injuries, it is widely accepted that impaired cough is a significant risk factor ${ }^{39}$.

As many as $30 \%$ of healthy elderly subjects may aspirate at least once during a sequential swallow paradigm, indicating that aspiration can occur even in the absence of pathology 40 . The occurrence of spontaneous cough in normal subjects may well be a response to these minor aspiration events. 


\section{Detection of dystussia and atussia}

Assessment of disordered cough is usually performed in context with an effort to predict competency of airway protective mechanisms in patients with neurologic disease. These assessments are most frequently based on subjective measures such as cough sounds with or without a water drinking challenge, and/or appearance of cough strength or quality during either voluntary or induced cough maneuvers ${ }^{30,41}$. These bedside tests can have highly variable sensitivities and specificities when compared to videofluoroscopy in predicting risk of aspiration ${ }^{30,42}$. In particular, cough sounds may have some utility in differentiating between patient groups with chronic cough and/or suppression of this behavior by antitussive drugs ${ }^{43}$, ${ }^{44}$. However, this approach is only useful in concert with advanced objective analytic methodologies, which can include computational analysis ${ }^{43}$, 44 . Subjective assessments represent an effort to simplify the measurement of a complex and multiphasic motor act that is produced by coordinated activation of a host of upper airway and chest wall muscles ${ }^{34}$. The occurrence of atussia in response to cough promoting stimuli probably lends itself to precise measurement by subjective observation. However, approaches that validate subjective assessments of dystussia by comparison to objective measures of cough mechanics are most likely to yield tests that have high sensitivities and specificities. Objective measures of cough mechanics have been shown to have high sensitivity and specificity in predicting risk of aspiration in patients with neurological disease ${ }^{30,35}$.

Voluntary cough can only be used in patients that are awake and capable of following verbal commands. Previous reports that have objectively analyzed voluntary cough in patients with neurological disease have employed instrumentation that acquired, filtered, and recorded cough airflows signals with high fidelity $30,35,37,45$. Although these recordings can be made at bedside, the instrumentation can be expensive. Presumably, less expensive handheld spirometers can be employed to acquire and process these signals, but this assumption has yet to be validated. Features of the cough airflow waveform that have been shown to be most useful in the evaluation of dystussia are peak expiratory airflow (PEA), expulsive flow rise-time

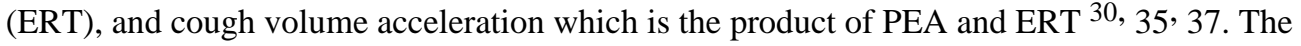
duration of the compression phase may a be useful measure of dystussia in some patient groups 37,45 , but not in others ${ }^{35}$. The duration of the compression phase during cough is difficult to measure by subjective observation, which highlights the importance of objective measurements of cough airflows in patients in which dystussia is suspected. Other methods for eliciting cough, such as challenge with irritant aerosols ${ }^{46}$, may also have significant value in identifying patients at risk of aspiration. As with voluntary cough, the ultimate value of this method will become clearer as our knowledge of the predictive nature of objective and subjective measures of coughing in patients at risk of aspiration increases.

\section{Treatment}

There are currently no FDA approved pharmacological treatments for enhancement of coughing in patients with dystussia or atussia. Most therapeutic strategies are centered on physical therapy techniques. In patients with spinal injuries, external movement of the chest wall and/or abdomen to increase expiratory airflows has been employed with limited efficacy ${ }^{47}$. Electrical stimulation of expiratory muscles has not been very effective, although recent trials of intrathecal electrical stimulation have proven effective in restoring expiratory airflow sufficient to simulate coughing ${ }^{48,}{ }^{49}$. As this is an invasive method, it is likely to be most appropriate for tetraplegic patients.

Other nonpharmacological approaches may have promise in restoring impaired cough. In patients with Parkinson's disease that have dysphagia and dystussia, expiratory muscle strength training has proven effective in improving peak expiratory airflows and rise-times during voluntary cough ${ }^{45}$. In patients with dysphagia, it is common to employ behavioral 
methodologies to improve swallow function, and these approaches can have significant therapeutic effects ${ }^{29}$. It is unknown if these methods also can improve cough, representing a "cross-behavioral" therapeutic effect.

It is well known that coughing can be elicited by inhalation of irritant chemicals, such as acidic solutions, capsaicin, as well as nebulized distilled water ${ }^{50}$. The production of cough in response to inhalation of an acidic aerosol has been used to assess risk of pneumonia in patients with acute stroke $^{46}$. In this study, cough was assessed by subjective measures. Sixteen percent of the patients with abnormal cough exhibited atussia in response to inhalation of acidic solutions ${ }^{46}$. However, Yamanda et $\mathrm{al}^{51}$ showed that elderly patients with a history of aspiration pneumonia have a reduced cough sensitivity to inhaled citric acid. Furthermore, these investigators showed that the urge-to-cough of these patients was reduced at low dosage ranges of citric acid ${ }^{51}$. Although this study was conducted in a small number of patients, it does raise the possibility that both sensory and motor components of coughing may be impaired for months after aspiration pneumonia. The extent to which inhalation of irritant chemicals could be used as a therapeutic modality to enhance cough in patients with dystussia and/or atussia is unknown. Presumably, these widely used tests for cough sensitivity could be employed repeatedly in patient groups that are at risk of aspiration and dystussia to enhance sensory feedback specific to airway protection. This approach would be analogous to "forced use" of paretic limbs in rehabilitation strategies for stroke patients ${ }^{52}$. Alternatively, responsive patients with dystussia could be challenged with inhaled irritants at standard intervals to promote coughing.

\section{Summary}

Low dose oral morphine can inhibit chronic cough, but the use of this opioid as an antitussive agent may be limited by its side effect profile. Several studies have questioned the value of inhaled irritants in understanding pathological cough and its response to antitussives. A new measure of cough, urge-to-cough has recently been identified and may become useful in understanding the mechanisms of cough production and suppression in the awake human. Some proposed mucolytic drugs may be useful to suppress cough as adjunct therapies in selected patient populations.

Dystussia is the impairment of cough and represents a life-threatening problem in patients with neurological disease. There is a strong association between dystussia and dysphagia and patients with both have a high risk for aspiration. There is a significant unmet need for more information regarding the diagnosis and treatment of dystussia and the mechanisms that underlie this breakdown in airway protection in patients with neurological diseases.

\section{Acknowledgments}

We thank Teresa Pitts for her valuable feedback on the manuscript.

This work was supported by R33 HL089104 from the National Institutes of Health.

\section{References}

1. Canning BJ. Central regulation of the cough reflex: therapeutic implications. Pulm Pharmacol Ther Apr;2009 22(2):75-81. [PubMed: 19284972]

2. Dicpinigaitis PV. Currently available antitussives. Pulm Pharmacol Ther Apr;2009 22(2):148-151. [PubMed: 18771744]

3. Chung KF. Chronic cough: future directions in chronic cough: mechanisms and antitussives. Chron Respir Dis 2007;4(3):159-165. [PubMed: 17711916] 
4. Chung KF. Effective antitussives for the cough patient: an unmet need. Pulm Pharmacol Ther 2007;20 (4):438-445. [PubMed: 17161637]

5. Chung KF. Currently available cough suppressants for chronic cough. Lung 2008;186:S82-87. [PubMed: 17909897]

6. Chung KF. Clinical cough VI: the need for new therapies for cough: disease-specific and symptomrelated antitussives. Handb Exp Pharmacol 2009;(187):343-368. [PubMed: 18825350]

7. Pavord ID, Chung KF. Management of chronic cough. Lancet Apr 19;2008 371(9621):1375-1384. [PubMed: 18424326]

8. Chung KF, Bolser D, Davenport P, Fontana G, Morice A, Widdicombe J. Semantics and types of cough. Pulm Pharmacol Ther Apr;2009 22(2):139-142. [PubMed: 19136069]

9. Bolser DC. Cough suppressant and pharmacologic protussive therapy: ACCP evidence-based clinical practice guidelines. Chest Jan;2006 129(1 Suppl):238S-249S. [PubMed: 16428717]

10. Irwin RS, Boulet LP, Cloutier MM, et al. Managing cough as a defense mechanism and as a symptom. A consensus panel report of the American College of Chest Physicians. Chest Aug;1998 114(2 Suppl Managing):133S-181S. [PubMed: 9725800]

11. Smith J, Owen E, Earis J, Woodcock A. Effect of codeine on objective measurement of cough in chronic obstructive pulmonary disease. J Allergy Clin Immunol Apr;2006 117(4):831-835. [PubMed: 16630941]

12. Morice AH, Menon MS, Mulrennan SA, et al. Opiate therapy in chronic cough. Am J Respir Crit Care Med Feb 15;2007 175(4):312-315. [PubMed: 17122382]

13. Davenport PW, Bolser DC, Vickroy T, et al. The effect of codeine on the Urge-to-Cough response to inhaled capsaicin. Pulm Pharmacol Ther 2007;20(4):338-346. [PubMed: 17292647]

14. Chau TT, Carter FE, Harris LS. Antitussive effect of the optical isomers of mu, kappa and sigma opiate agonists/antagonists in the cat. J Pharmacol Exp Ther Jul;1983 226(1):108-113. [PubMed: 6864534]

15. Ramsay J, Wright C, Thompson R, Hull D, Morice AH. Assessment of antitussive efficacy of dextromethorphan in smoking related cough: objective vs. subjective measures. Br J Clin Pharmacol May;2008 65(5):737-741. [PubMed: 18279476]

16. Davenport PW. Clinical cough I: the urge-to-cough: a respiratory sensation. Handb Exp Pharmacol 2009;(187):263-276. [PubMed: 18825345]

17. Hutchings HA, Eccles R. The opioid agonist codeine and antagonist naltrexone do not affect voluntary suppression of capsaicin induced cough in healthy subjects. Eur Respir J Apr;1994 7(4):715-719. [PubMed: 8005254]

18. Hutchings HA, Eccles R, Smith AP, Jawad MS. Voluntary cough suppression as an indication of symptom severity in upper respiratory tract infections. Eur Respir J Nov;1993 6(10):1449-1454. [PubMed: 8112437]

19. Karlsson JA, Zackrisson C, Lundberg JM. Hyperresponsiveness to tussive stimuli in cigarette smokeexposed guinea-pigs: a role for capsaicin-sensitive, calcitonin gene-related peptide-containing nerves. Acta Physiol Scand Apr;1991 141(4):445-454. [PubMed: 1877346]

20. Kou YR, Frazier DT, Lee LY. The stimulatory effect of nicotine on vagal pulmonary C-fibers in dogs. Respir Physiol Jun;1989 76(3):347-356. [PubMed: 2749033]

21. Lee LY, Gu Q. Cough sensors. IV. Nicotinic membrane receptors on cough sensors. Handb Exp Pharmacol 2009;(187):77-98. [PubMed: 18825337]

22. Davenport PW, Vovk A, Duke RK, Bolser DC, Robertson E. The urge-to-cough and cough motor response modulation by the central effects of nicotine. Pulm Pharmacol Ther Apr;2009 22(2):82-89. [PubMed: 19100331]

23. Cummings KM, Giovino G, Jaen CR, Emrich LJ. Reports of smoking withdrawal symptoms over a 21 day period of abstinence. Addict Behav 1985;10(4):373-381. [PubMed: 4091070]

24. Ghanei M, Shohrati M, Jafari M, Ghaderi S, Alaeddini F, Aslani J. N-acetylcysteine improves the clinical conditions of mustard gas-exposed patients with normal pulmonary function test. Basic Clin Pharmacol Toxicol Nov;2008 103(5):428-432. [PubMed: 18801028]

25. Balli F, Bergamini B, Calistru P, et al. Clinical effects of erdosteine in the treatment of acute respiratory tract diseases in children. Int J Clin Pharmacol Ther Jan;2007 45(1):16-22. [PubMed: 17256446] 
26. Dal Negro RW, Visconti M, Micheletto C, Tognella S. Changes in blood ROS, e-NO, and some proinflammatory mediators in bronchial secretions following erdosteine or placebo: a controlled study in current smokers with mild COPD. Pulm Pharmacol Ther 2008;21(2):304-308. [PubMed: 17889580]

27. Dicpinigaitis PV, Spinner L, Santhyadka G, Negassa A. Effect of tiotropium on cough reflex sensitivity in acute viral cough. Lung Nov-Dec;2008 186(6):369-374. [PubMed: 18787899]

28. Casaburi R, Briggs DD, Donohue JF, Serby CW, Menjoge SS, Witek TJ. The spirometric efficacy of once-daily dosing with tiotropium in stable COPD. Chest 2000;118:1294-1302. [PubMed: 11083677]

29. Smith Hammond CA, Goldstein LB. Cough and aspiration of food and liquids due to oral-pharyngeal dysphagia: ACCP evidence-based clinical practice guidelines. Chest Jan;2006 129(1 Suppl):154S168S. [PubMed: 16428705]

30. Smith Hammond CA, Goldstein LB, Horner RD, et al. Predicting aspiration in patients with ischemic stroke: comparison of clinical signs and aerodynamic measures of voluntary cough. Chest Mar;2009 135(3):769-777. [PubMed: 19017886]

31. Logemann JA. Swallowing physiology and pathophysiology. Otolaryngol Clin North Am Nov;1988 21(4):613-623. [PubMed: 3054716]

32. Paydarfar D, Gilbert RJ, Poppel CS, Nassab PF. Respiratory phase resetting and airflow changes induced by swallowing in humans. J Physiol Feb 15;1995 483(Pt 1):273-288. [PubMed: 7776238]

33. Korpas, J.; Tomori, Z. Cough and other respiratory reflexes. Basel; New York: S. Karger; 1979.

34. Leith, DE.; Butler, JP.; Sneddon, SL.; Brain, JD. Handbook of Physiology. The Respiratory System,V. III. Mechanics of Breathing, Part I. Bethesda: American Physiological Society; 1986. Cough; p. 315-336.

35. Smith Hammond CA, Goldstein LB, Zajac DJ, Gray L, Davenport PW, Bolser DC. Assessment of aspiration risk in stroke patients with quantification of voluntary cough. Neurology Feb 27;2001 56 (4):502-506. [PubMed: 11222795]

36. Scannapieco FA. Role of oral bacteria in respiratory infection. J Periodontol Jul;1999 70(7):793-802. [PubMed: 10440642]

37. Pitts T, Bolser D, Rosenbek J, Troche M, Sapienza C. Voluntary cough production and swallow dysfunction in Parkinson's disease. Dysphagia Sep;2008 23(3):297-301. [PubMed: 18483823]

38. Pikus L, Levine MS, Yang YX, et al. Videofluoroscopic studies of swallowing dysfunction and the relative risk of pneumonia. AJR Am J Roentgenol Jun;2003 180(6):1613-1616. [PubMed: 12760930]

39. Schilero GJ, Spungen AM, Bauman WA, Radulovic M, Lesser M. Pulmonary function and spinal cord injury. Respir Physiol Neurobiol May 15;2009 166(3):129-141. [PubMed: 19442929]

40. Butler SG, Stuart A, Markley L, Rees C. Penetration and aspiration in healthy older adults as assessed during endoscopic evaluation of swallowing. Ann Otol Rhinol Laryngol Mar;2009 118(3):190-198. [PubMed: 19374150]

41. Smith Hammond C. Cough and aspiration of food and liquids due to oral pharyngeal Dysphagia. Lung 2008;186:S35-40. [PubMed: 18196338]

42. Ramsey DJ, Smithard DG, Kalra L. Early assessments of dysphagia and aspiration risk in acute stroke patients. Stroke May;2003 34(5):1252-1257. [PubMed: 12677020]

43. Pavesi L, Subburaj S, Porter-Shaw K. Application and validation of a computerized cough acquisition system for objective monitoring of acute cough: a meta-analysis. Chest Oct;2001 120(4):1121-1128. [PubMed: 11591548]

44. Piirila P, Sovijarvi AR. Differences in acoustic and dynamic characteristics of spontaneous cough in pulmonary diseases. Chest Jul;1989 96(1):46-53. [PubMed: 2736992]

45. Pitts T, Bolser D, Rosenbek J, Troche M, Okun MS, Sapienza C. Impact of expiratory muscle strength training on voluntary cough and swallow function in Parkinson disease. Chest May;2009 135(5): 1301-1308. [PubMed: 19029430]

46. Addington WR, Stephens RE, Widdicombe JG, Rekab K. Effect of stroke location on the laryngeal cough reflex and pneumonia risk. Cough Aug 4;2005 1:4. [PubMed: 16270928]

47. Jaeger RJ, Turba RM, Yarkony GM, Roth EJ. Cough in spinal cord injured patients: comparison of three methods to produce cough. Arch Phys Med Rehabil Dec;1993 74(12):1358-1361. [PubMed: 8018145] 
48. DiMarco AF, Kowalski KE, Geertman RT, Hromyak DR. Lower thoracic spinal cord stimulation to restore cough in patients with spinal cord injury: results of a National Institutes of Health-sponsored clinical trial. Part I: methodology and effectiveness of expiratory muscle activation. Arch Phys Med Rehabil May;2009 90(5):717-725. [PubMed: 19406289]

49. DiMarco AF, Kowalski KE, Geertman RT, et al. Lower thoracic spinal cord stimulation to restore cough in patients with spinal cord injury: results of a National Institutes of Health-Sponsored clinical trial. Part II: clinical outcomes. Arch Phys Med Rehabil May;2009 90(5):726-732. [PubMed: 19406290]

50. Dicpinigaitis PV. Experimentally induced cough. Pulm Pharmacol Ther 2007;20(4):319-324. [PubMed: 17113801]

51. Yamanda S, Ebihara S, Ebihara T, et al. Impaired urge-to-cough in elderly patients with aspiration pneumonia. Cough 2008;4:11. [PubMed: 19019213]

52. Nudo RJ, Friel KM. Cortical plasticity after stroke: implications for rehabilitation. Rev Neurol (Paris) 1999;155(9):713-717. [PubMed: 10528355] 
Table 1

Influence of selected agents on cough

\begin{tabular}{|l|l|l|}
\hline Drug & Mechanism & Outcome \\
\hline Codeine & Opioid & No effect on cough due to COPD \\
\hline Morphine & Opioid & $\begin{array}{l}40 \% \text { decrease in cough in patients with chronic cough refractory to specific } \\
\text { therapy, well tolerated but long term use potentially limited by side effects }\end{array}$ \\
\hline Dextromethorphan & Nonopioid & $\begin{array}{l}\text { Slight but significant decrease in cough due to upper airway disorders, no } \\
\text { effect on smoker's cough }\end{array}$ \\
\hline N-acetylcysteine & Antioxidant? & Significant cough alleviation in patients with chemical injury to lungs \\
\hline Erdosteine & Antioxidant? & Potentiates cough suppressant effect of antibiotics during airway infection \\
\hline Tiotropium & Unknown & Decreased capsaicin sensitivity, no effect on cough due to COPD \\
\hline
\end{tabular}


Table 2

Important terms in airway protection

\begin{tabular}{|l|l|}
\hline Term & Definition \\
\hline Airway protection & Prevention and/or correction of aspiration \\
\hline Dystussia & Impaired cough \\
\hline Atussia & Inability to cough \\
\hline Silent aspiration & Aspiration with atussia \\
\hline
\end{tabular}

